\title{
XXV-th Congress on Spectroscopy: preface
}

\author{
A.V. Naumov ${ }^{1-3,{ }^{*}}$, K.R. Karimullin ${ }^{1,2}$, and E.A. Vinogradov ${ }^{1,3}$ \\ ${ }^{1}$ Institute for Spectroscopy RAS, 108840 Moscow, Troitsk, Russia \\ ${ }^{2}$ Moscow State Pedagogical University, 119991 Moscow, Russia \\ ${ }^{3}$ Moscow Institute of Physics and Technology, 142700 Dolgoprudny, Russia
}

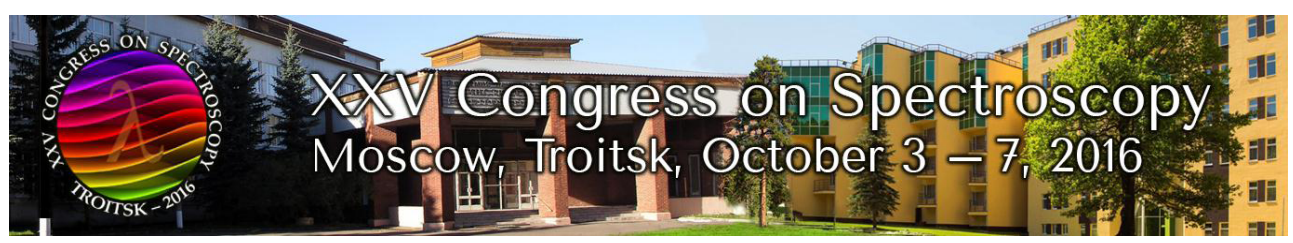

The Congress on Spectroscopy is a regular quadrennial scientific meeting. The series was started in the Soviet Union in 1930-th and has been carefully continued. Nowadays the Congress brings together participants from Russia, neighboring countries (the former Soviet republics) and guests from other countries worldwide. Traditionally, the Congress aims at giving an overview of all areas of modern optics and spectroscopy as well as the latest and topical achievements in these and related disciplines. In previous years, the main organizer of this meeting was the Institute for Spectroscopy of the Russian Academy of Sciences (www.isan.troitsk.ru).

The XXV-th Congress on spectroscopy was held in Troitsk city district of Moscow (Russia) from $3^{\text {rd }}$ till $7^{\text {th }}$ October 2016 on the base of the Institute for Spectroscopy RAS.

The Congress program covered a broad range of actual questions of optics and spectroscopy, including fundamental atomic and molecular spectroscopy, spectroscopy of condensed matter and plasma, spectroscopy and microscopy of single quantum objects and nanostructures. Various interdisciplinary fields were also included and suggested for discussions during the meeting: quantum informatics, nanoplasmonics and metamaterials, nanooptics, photonics, applied spectroscopy in bio- and medical physics. Some special attention was paid to the questions of modern spectral instrumentation.

As a side event to the Congress there was the Youth Scientific School on Optics and Spectroscopy that offered a series of lectures and included talks of young scientists followed by a competition of their scientific works. The school was organized with help of the Moscow State Pedagogical University (www.mspu.ru).

The Congress was also accompanied with the exhibition organized by sponsoring companies, where the modern equipment for optics, spectroscopy and related areas from the world-wide leading manufacturers was demonstrated.

The scientific program of the meetings included 25 invited lectures, 54 oral talks, 112 poster talks, authored in total by 605 scientists from 16 countries (Russia, Belarus, Armenia, Ukraine, Italy, Germany, France, Austria, Poland, Czech Republic, Sweden, India, China, Japan, Australia, USA).

\footnotetext{
*Corresponding author: naumov@isan.troitsk.ru; web-page: www.spectroscopy.su
} 
This issue of the EPJ Web of Conferences consists of the expanded version of abstracts of the selected talks presented at the Congress. The issue is recommended for specialists who work in the field optics and spectroscopy, as well as for M.S. and Ph.D. students. The full program and details about the Congress can be found on the web-site www.spectroscopy.su). The next $26^{\text {th }}$ Congress will be organized by the Institute for Spectroscopy RAS in 2020.

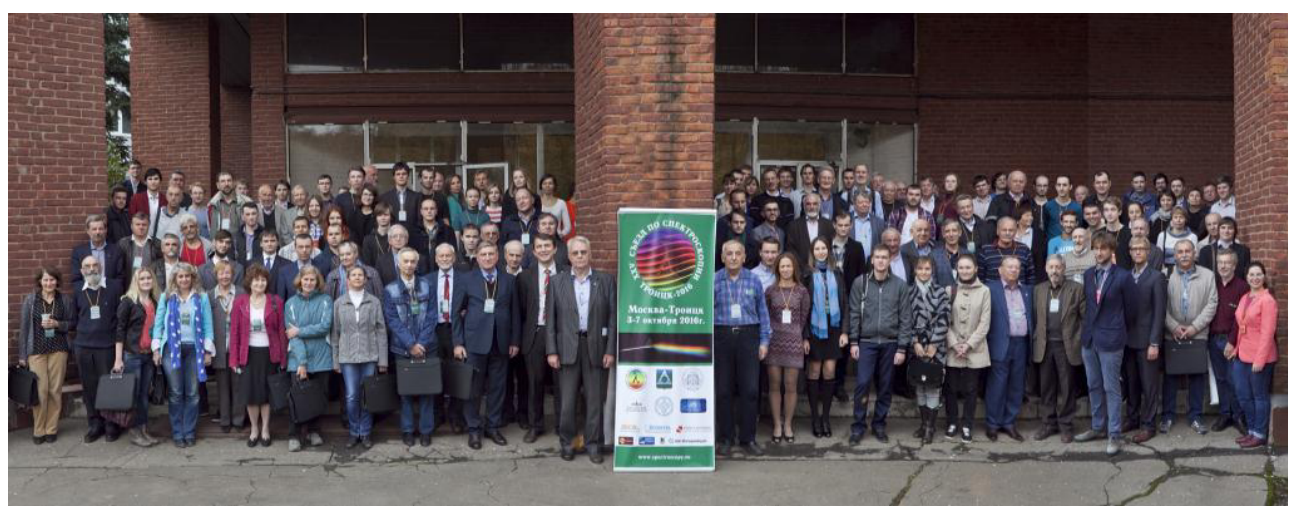

The general photo of the $25^{\text {th }}$ Congress on Spectroscopy.
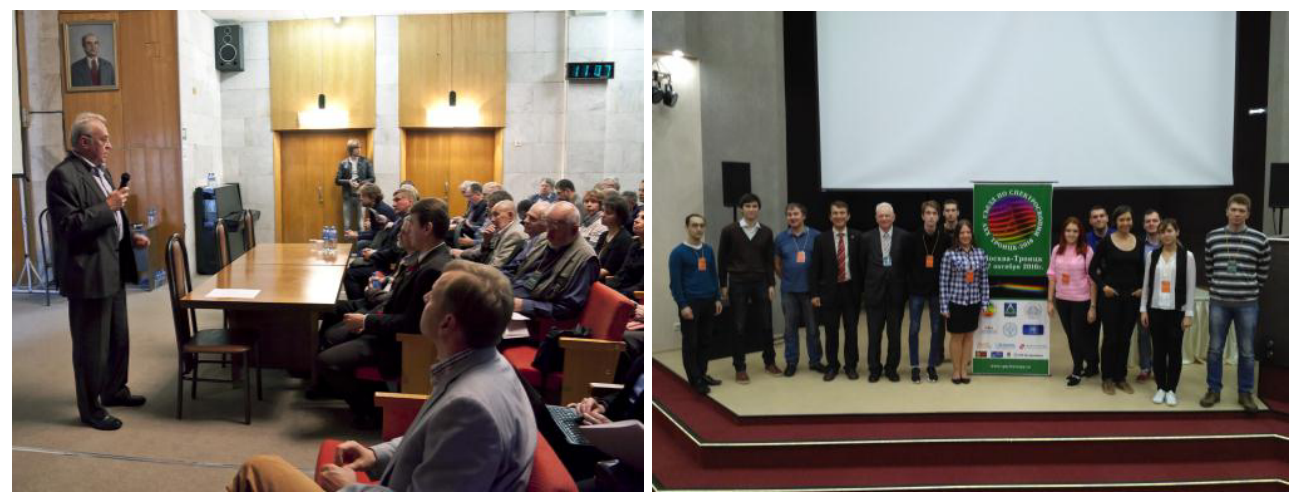

Opening session (left). The organizing committee (right).

The financial support is acknowledged from the Federal Agency of Scientific Organisations of Russian Federation and from Russian Foundation of Basic Researches (16-02-20722 - support of the Congress; 16-32-10405 - support of Youth scientific school).

The local organising committee of the Congress is a part of the leading scientific school of Russia NSh-7035.2016.2 "Spectroscopy of atoms, molecules and condensed matter".

The meeting and school were also sponsored by several companies: "Avesta Project" (manufacturing of lasers and optical components, www.avesta.ru); "Azimuth Photonics" (distribution of optoelectronics components, devices and research equipment for the photonics industry, www.azimp.ru); "Fizmatlit" (the publishing house, www.fml.ru); "Scontel" (manufacturing of the single photon detectors, www.scontel.ru); "SOL Instruments" (manufacturing of technologically advanced instruments for spectroscopy and related fields, www.solinstruments.com); "YE-International" (distribution of electronics and electromechanical components, measuring devices, instruments, power supplies, tools and accessories, www.yeint.ru). 